\title{
ESTADO ATUAL DA QUESTÃO DAS CROMICOSES
}

\author{
DR. FLORIANO DE ALMEIDA \\ Docente Livre e $10^{\circ}$ Assistente do Departamento de Microbiologia da Facul- \\ dade de Medicina da Universidade de São Paulo
}

Em fins de 1935, em colaboração com Morris Moore, estudamos o problema da icromomicose, no ponto de vista micológico. Verificamos então que nessa época a questão se apresentava um pouco confusa, pois várias denominações eram dadas aos agentes da cromomicose.

Assim, tinhamos de um lado, Phialophora verrucosa Thaxter \& Medlar 1915, denominação dada a um fungo encontrado primeiramente nos Estados Unidos e posteriormente no Uruguay, fungo êsse que se caracterisava por sua reprodução, isto é formação endogena de conidios, originados em conidióforos em forma de taças. Esta espécie segundo Conant \& Martin, "difere das outras formas pela reprodução de conidios unicamente em conidióforos em taça; este é o unico tipo de formação de conidios conhecidos desta forma"

De outro lado vários fungos eram incriminados como responsaveis pelos demais casos de cromomicose. Em ordem cronológica tinhamos entre outros os seguintes: Hormodendrum Pedrosoi, Brumpt 1921, Acrotheca Pedrosoi Terra, Torres, Fonseca \& Leão 1922, Trichosporium Pedrosoi Langeron 1929, Hormodendrum Pedrosoi Carrion 1936 e Hormodendrum compactum Carrion 1936.

Para a primeira denominação passou em 1921 o cogumelo que no ano precedente Pedroso \& Gomes consideraram como Phialophora verrucosa e que èra responsavel pelos quatro primeiros casos desses autores; digo desses autores porque, em 1915 Jesuino Maciel tambem em São Paulo, observou um caso clínico que considerou como pé de Madura. A cultura obtida foi considerada por Pinoy como uma Torula negra, provavelmente do gênero Cladosporium.

Estudando o cogumelo do primeiro caso de Pedroso, Brumpt classificou-o como Hormodendrun embora afirmasse existirem caracteres morfológicos suficientes para crear um novo gênero entre Hormodendrum e Cladosporium.

No ano seguinte, 1922, Terra, Torres, Fonseca \& Leão estudaram um caso, clínica e micológicamente, e julgaram dever o fungo isolado pertencer ao gênero Acrotheca. No ano seguinte os dois ultimos autores passaram para a sinonímia de Acrotheca Pedrosoi todas as denominações dadas aos cogumelos dos casos brasileiros de 
cromomicose. Essa ultima denominação foi aceita sém comentarios, porém, em 1929 Langeron estudando culturas de casos brasileiros concluiu pertencerem elas ao gênero Trichosporium e não Acrotheca.

Em 1935 e 1936 Carrion, só ou em colaboração com Emmons, em pesquisas realisadas em Porto Rico, após um estudo micológico cuidadoso de várias amostras achou que os casos' de cromomicose conhecidos eram determinados por cogumelos do gênero Phialophora e H.ormodendrum.

Desse estudo ficou estabelecido que o gênero Phialophora se manteria comó até então, isto é, como havia sido descrito por Thaxtèr \& Lane em 1915, porém o gênero Hormodendrum deveria daí em diante ser ampliado, isto é, nele deveriam ser incluidos cogumelos que, além da fórma cclássica de reprodução do tipo Hormodendrum, tivessem também a fórma de reprodução de Phialophora isto é, conidióforos em taças.

Ficavamos assim com um gênero em que algumas amostras apresentavam conidióforos em taça, ao pass@ que outras não apresentavam.

Além disso a espécie $H$. compactum de Carrion ainda apresentava outro fórma de reprodução que era o conidióforo em cajado nodoso, até então típico de Acrotheca.

$H$. compactum era assim. uma espécie que apresentava orgãos de reprodução característicos de tres gêneros, Phialophora, Hormodendrum e Acrotheca.

Quando em 1935 com Morris Moore realisamos nossas pesquisas, Carrion \& Emmons realisavam também as suas em Porto Rico.

Iniciando nosso estudo micológico das amostras da micoteca do Departamento de Microbiologia e Imunologia da Faculdade de Medicina da Universidade de São Paulo, vimòs logo que vários gêneros deveriam ser considerados. Primeiro, o gênero Phialophora com a espécie verrucosa constituida pelas duas amostras norte-americanas, mais a uruguaia de MacKinnon. Depois, por úma outra espécie desse mesmo gênero, Phialophora macrospora (fig. 1) e que fôra isolada por Pedroso de um de seus casos. Verificamos depois que o gênero Acrotheca nada tinha a ver com os cogumelos isolados dos casos de cromomicose. Êste nosso modo de ver, naquela época, é hoje aceito por todos os pesquisadores. Algumas amostras classificadas como Acrotheca tinham certa semelhança com Botrytis mas neste gênero não podiam ser colocadas. Creámọs então o gênero Botrytoides espécie monophora; caracterisado pelo conidióforo em cajado nodoso, que podia ser mediano, terminal ou lateral. Ver fig. 2 números $24,26,27$ respectivamente.

Uma cultura com o nome Trichosporium Pedrosoi recebida de Langeron em 1936 e como as outras estudada em meio de Czapek conforme haviam preconisado Fonseca \& Leão, apresentou-nos for- 

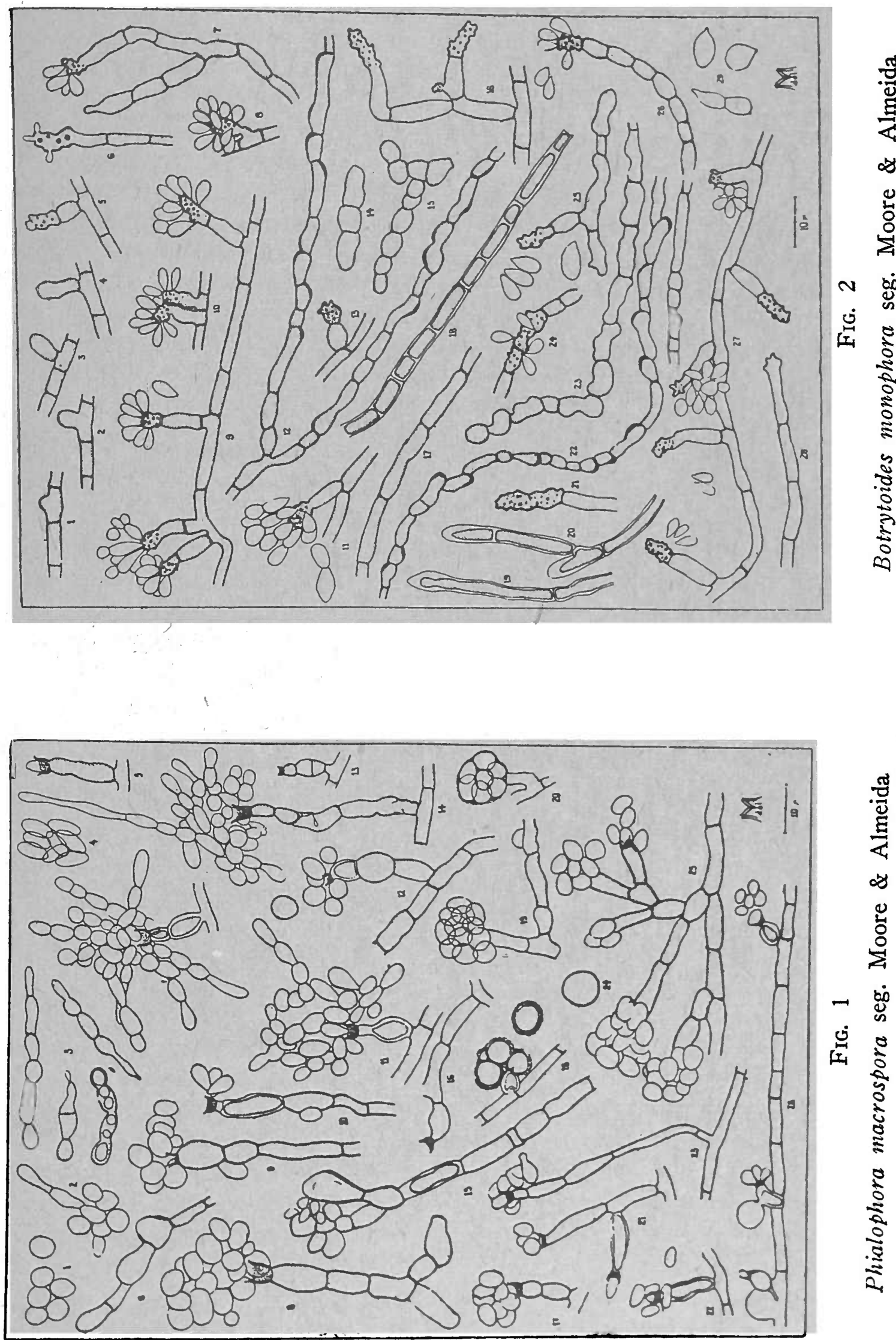

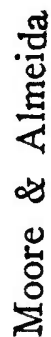

$-\quad \dot{8}$

兽

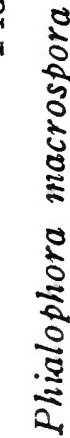


mas de reprodução pertiencentes quer ao gênero Hormodendrum quer ao Botrytoides. Não podendo mante-la no gênero Trichosporium nem coloca-la em H:ormodendrum ou Botrytoides, creámos o gênero Hormodendroides. Finalmente uma outra cultura apresentou-nos formas de reprodução típicas de tres gêneros, Phialophora, Hormodendrum e Botryoides. Onde coloca-la?' Naturalmente em um nove gênero. Foi o quie fizemos creando Phialoconidióphora Guggenhei. mia (fig. 3). Verificamos depois pela análise dos trabálhos de Carrion \& Emmons que a espécie Hormodendrum compactum apresentava formas de reprodução que permitiam coloca-la no gênero Phialoconidióphora. Aí classificamos provisoriamente como $P$. compactum (Carrion) Moore \& Almeida 1936.

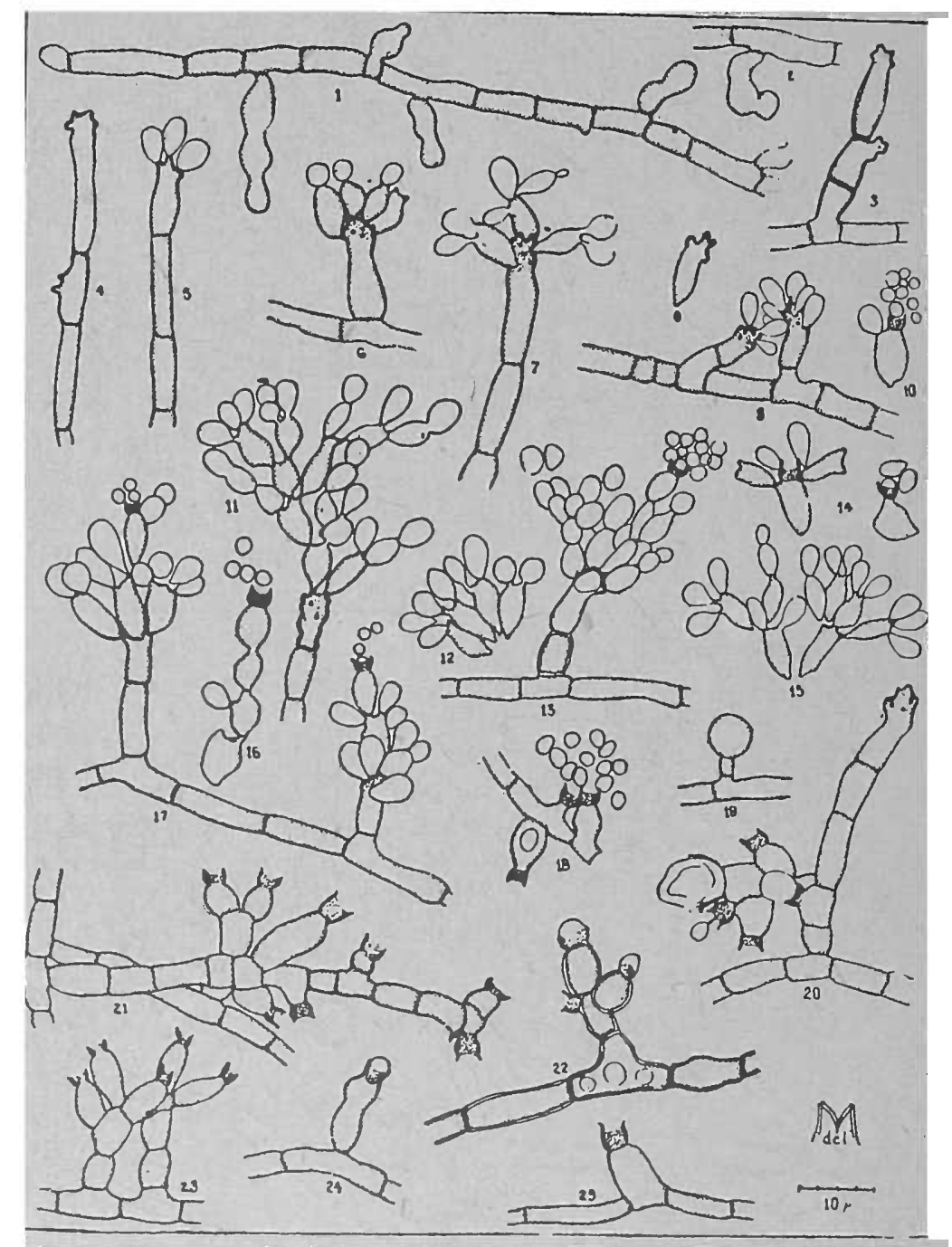

FIG. 3

Phialoconidiophora Guggenheimia seg. Moore \& Almeida

Ainda nesse mesmo ano de 1936, Negroni na Argentina reestudou a amostra isolada do primeiro caso argentino de cromomicose e verificou que ela não devia pertencer, a Acrotheca como supuzera a principio, mas devería pertencer a um novo gênero que chamou 
Fonsecaea espécie Pedrosoi, pois apresentava conidióforos de Hormodendrum e de Acrotheca ou Botrytoides. O novo gênero Fonsecaea de Negroni é identico a Hormodendroides Moore \& Almeida. Publicado, porém, no número de Março de 1936 da Revista del Inst. Bacteriologico del Dep. Nac. de Higiene de Buenos Aires (**) embora tenha sido entregue para a publicação em Agosto desse mesmo ano, o gênero Fonseciaea tem a prioridade sobre Hormodendroides Moore \& Almeida, porque êște só foi publicado no Miss. Bot. Garden, número de Novembro do mesmo ano. Um estudo de confronto dessa amostra de Negroni com outras nossas está sendo feito por nós atualmente.

Em 1937 Conant \& Martin realizaram um estudo morfológico e imunológico de 17 amostras de cogumelos isolados de cromomicose com a seguinte origem:

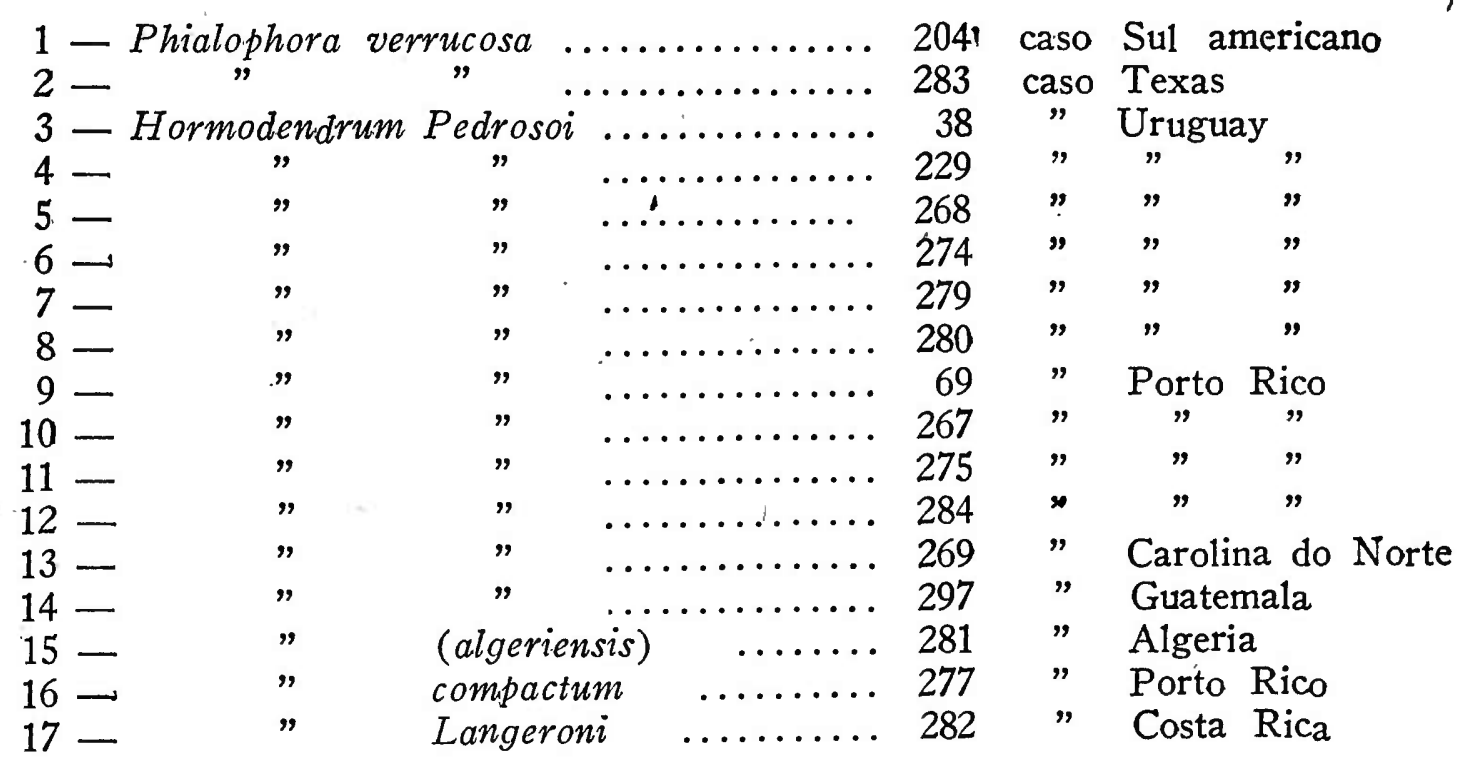

Como vemos, figuram na lista 12 amostras de $H$. Pedrosoi sendo apenas seis sul americanas. A amostra número $15, H$. algeriensis é considerada pelos autores como $H$. Pedrosoi.

Pelo estudo realisado julgam êsses autores que os referidos cogumelos devem pertencer aos 4 tipos seguintes:

\section{1 - Phialophora verrucosa \\ 2 - Hormodendrum Pedrosoi \\ 3 - Hormodendrum compactum \\ 4 - Hormodendrum Langeroni}

Realisaram aqueles autores provas sôrológicas com 5 sôros preparados com 2 amostras de Hormodendrum Pedrosoi e uma de cada uma das outras 3 culturas As duas amostras de $H$. Pedrosoi consideradias como típicas, eram uma isolada nos Estados Unidos e a outra na Algeria, e denominada anteriormente $H$. algeriensis.

(**) Numero êste saído com grande atraso. 
Êste fato é apenas aquí referido, porém, não o comentamos.

Cómo se depreende do exposto são unanimes os autores em admitir que numerosos cogumelos podem causar cromomicose. Pelas observações que ha vários anos vimos realisando sobre essa questão parece-nos muito mais lógico colocar no gênero Phialophọra e não em Hormodendrum as espécies que apresentam conidióforos em taça. Outros autores preferiram, porém, considera-1as como $\dot{H}$. Pedrosoi, embora para esta espécie Brumpt não assinalasse conidióforos em taças. Pareceu-nos portanto muito mais razoavel crear novos gêneros. para os cogumelos que apresentassem orgãos de reprodução característicos de tres gêneros ou de dois sómente, do que coloca-los como amostras de uma espécie, ao lado de outras amostras que podem ou não apresentar todos êsses elementos. Conant \& Martin, seguiram a orientação de Carrion \& Emmons e estudaram como vimos 13 amostras que consideraram como $H$. Pedrosoi. Nelas encontram taças apenas em oito. Das outras 5 amostras 4 eram sul americanas e a ultima africana $H$. algeriensis que os referidos autores consideram também $H$. Pedrosoi.

Parece-nos, que esta simplificação apenas trouxe complicações. Para esclarecimento definitivo do assunto achamos que deve ser feito um estudo morfológico comparativo cuidadoso do maior número de amostras possivel. Assim se estabeleceriam bases seguras para o futuro.

Vê-se pelo que ficou dito que, para se ter uma noção mais ou mevios segura do assunto é necessario realizar um trabalho de laboratorio cuidadoso e isento dé qualquer idéia preconcebida. Não basta compulsar a literatura.

Esperamos poder em breve voltar a esta interessante questâo trazendo uma nova contribuição pessoal sobre o estudo morfológico de grande número de amortras de cogumelos isolados de casos de cromomicose, nacionais e extrangeiros. 